\title{
Un análisis sobre la eficacia de la construcción jurídica de inimputabilidad en la matanza de Lonco Luán. El poder de perdonar
}

RMA

Antropología Social
Andrea N. Lombraña

CONICET, Sección Etnología, Instituto de Ciencias Antropológicas, Facultad de Filosofía y Letras, Universidad de Buenos Aires.

E-mail: andrealombrana@conicet.gov.ar

\begin{abstract}
Resúmen
El Código Penal argentino considera la prohibición normativa del uso de la violencia privada, aunque simultáneamente ofrece cierta disminución de la reprochabilidad (en términos de responsabilidad penal) a través de la atenuación de penas o inclusive la declaración de inimputabilidad, si su uso viene acompañado de cierto componente emocional intenso. El presente artículo propone analizar y evaluar dichas consideraciones como formas institucionalizadas y codificadas de "perdón". Con base en una lectura crítica del expediente del caso La Matanza de Lonco Luán - y prestando especial atención a las declaraciones de los imputados, las pericias técnicas, los alegatos de las partes y la sentencia del magistrado - se sostiene que estas formas de perdón son resultado de transcursos históricos determinados y que constituyen dispositivos altamente eficaces en el establecimiento de jerarquías sociales y en el proceso de mantenimiento del orden. La perspectiva metodológica adoptada supone el desarrollo de una lectura antropológica de la causa judicial, analizándola principalmente como ámbito de producción de sentido; que, como tal, expresa los juegos de circulación y disputa de bienes simbólicos, y refuerza a la vez la estructura de posiciones sociales.
\end{abstract}

Palabras Clave: Derecho; violencia; emoción; perdón; poder.

An analysis of the effectiveness of the legal construction of criminal responsibility in the killing of Lonco Luán. The power of forgiving.

\begin{abstract}
The Argentine Penal Code considers the normative prohibition about the use of the private violence, although it offers certain reduced blameworthiness (in terms of criminal responsibility) through the attenuation of pains or the declaration of incompetent, if its use comes accompanied from certain intense emotional component. The present article proposes to analyze and to evaluate these considerations as institutionalized and codified forms of "pardon". Based on a critical reading of the file of the case "La Matanza de Lonco Luán" - and paying special attention to the declarations of the imputed ones, the technical skills, the pleas of the interested parties and the sentence of the judge -it is argued that these forms of pardon are been determined from historical courses and also they highly constitute effective devices in the establishment of social hierarchies and the process of maintenance of order. The adopted methodological perspective supposes the development of an anthropological reading of the judicial cause, analyzing it mainly like scope of sense production; as such it express the games of circulation and dispute of symbolic goods, and reinforces the structure of social positions simultaneously.
\end{abstract}

Keywords: Rights; violence; emotion; pardon; power.

\section{La matanza de Lonco Luán y sus contextos}

El 24 de agosto de 1978 en la comunidad indígena mapuche de Lonco Luán, tiene lugar una reunión religiosa con el fin de lograr la cura de una de sus integrantes, que padecía una dolencia física persistente. Luego de varias jornadas de oración y un extenso ayuno, resultan agredidos varios integrantes del grupo. La primera víctima es una niña de once años que recibe diversos golpes que le ocasionan la muerte, luego es atacado un joven de 14 años también a golpes, que logra huir; unos minutos más tarde son agredidos simultáneamente un niño de 5 años, que recibe varios palazos de madera que le producen traumatismos craneanos graves, y otro de 2 años quien sufre el ataque de varios hachazos, resultando ambos fallecidos; finalmente una mujer de 25 años es agredida con un gancho de hierro hasta su defunción. Algunos vecinos no indígenas que advierten la situación, dan aviso

Recibido 04-07-2010. Recibido con correcciones 30-04-2011. Aceptado 17-08-2011 
a las autoridades policiales locales quienes finalmente intervienen, y luego de extenuantes esfuerzos logran detener la matanza.

Esta reconstrucción de los hechos que puede leerse en el parte policial que la comisaría de Aluminé envía a la regional II de la ciudad de Zapala el 28 de agosto de 1978, es el primer documento incorporado al expediente 5413 de 1 ra. Instancia del Juzgado Penal de Zapala de la $3^{\circ}$ Circunscripción de la Provincia de Neuquén?.

Una de las primeras impresiones que el documento describe en relación al asentamiento donde ocurren los hechos, es el despliegue de viviendas muy precarias construidas de adobe con algunos galpones y corrales circulares a su alrededor. Esta ocupación del espacio está relacionada con la actividad económica tradicional de "crianceros" o cría de ganado menor (Radovich 1983). La baja calidad de las tierras ocupadas y el arrinconamiento ecológico resultado de años de persecución sistemática de estos pueblos, podrían explicar el empobrecimiento y las condiciones que encontró la policía al llegar al lugar.

Cabe recordar que la conformación de un Estado nacional, supuso el ideario de la integración de todas las regiones que ahora constituyen la Argentina y fundamentalmente la inclusión de la mal llamada "zona del desierto". La integración fue el dogma imperante, tanto a nivel político como religioso; que en una zona fronteriza como esta presentó un carácter particular: "La convivencia fue obligatoria, porque todos estaban ahí, los de antes y los recién llegados. Fue un encuentro no deseado por ninguno de los protagonistas. Los que eran nuevos hubieran deseado que los antiguos pobladores ya no estuvieran más, evitándose el contacto problemático con costumbres y derechos adquiridos que nunca les fueron reconocidas. Y los que eran los viejos pobladores, los que estuvieron desde siempre, necesitaron un cambio radical, desde las formas de percibir el mundo hasta las mañas que se necesitaban para limitar las ansias de poder de esta nueva gente. "(Kalinsky y Cañete 2000: 5).

Según se desprende también de la lectura del expediente, los protagonistas de los acontecimientos eran seguidores de la Unión Pentecostal. Es interesante comentar, que este culto evangélico llega a la región a través de la inmigración de pastores y campesinos chilenos a la Patagonia argentina aproximadamente en los años 60, avanzando rápidamente sobre las poblaciones indígenas mapuche rurales y los sectores económicamente más carenciados en las áreas urbanas y periurbanas de la provincia de Neuquén (Radovich: 1983).

\footnotetext{
1 El expediente judicial de referencia constituye el campo de trabajo y fuente principal de datos del artículo. Sin embargo, dada la gran repercusión del caso, existen una gran cantidad de artículos periodísticos, papers científicos y otros documentos que han abordado los sucesos desde diferentes perspectivas. La lectura de estos materiales, ha nutrido de información muy valiosa las reflexiones del presente trabajo.
}

Varios autores han intentado explicar este alto grado de adscripción esgrimiendo explicaciones de diversa índole. Los trabajos de Rolf Foerster (1993) por ejemplo, sostienen que el pentecostalismo ha significado una respuesta activa a la conquista y a la dominación colonial, constituyéndose como una forma de re-elaborar la propia identidad étnica mapuche. De hecho, las manifestaciones religiosas pentecostales presentan una serie de continuidades con la religiosidad tradicional del mapuche, al menos en tres ejes fundamentales: la lucha entre el bien y el mal; el papel de los antepasados y el sentido de la comunidad ritual (Foerster 1993).

No es menor hacer notar por otro lado, que todo el proceso judicial se encuentra atravesado por los acontecimientos políticos y sociales que se desarrollaron durante la última dictadura militar en Argentina (1976-1983); y que entre las estrategias represivas implementadas en la época, la creación e implementación de reglamentaciones jurídicas de mayor alcance punitivo fue fundamental (D'Antonio 2008).

En este contexto, muchas de las producciones teóricocientíficas de la escena nacional contribuyeron en la fundamentación de las decisiones de los tribunales y nutrieron los discursos jurídicos de la época. El expediente de Lonco Luán en este sentido, debe ser leído a la luz de la notable influencia de la etnología fenomenológica ${ }^{2}$ por un lado - que se proponía como programa científico, el rescate de todo indicio que permitiese reconstruir la historia prehispánica desde un punto de vista evolutivo y unificó la vida de los indígenas en el presente (caracterizados como "bárbaros"), los restos materiales de su actividad pasada y las creencias folklóricas bajo una misma lógica (Visacovsky, Guber y Gurevich 1997) - y la incidencia de un discurso indigenista emergente representado fundamentalmente por la Asociación Indígena de la República Argentina, que defendió en este caso la tesis de la inimputabilidad por incomprensión de la criminalidad, atribuyendo responsabilidad a una errónea predicación y al choque de cosmovisiones ${ }^{3}$.

\section{Sobre la inimputabilidad penal (derecho y emoción)}

Abordar la inimputabilidad jurídica supone reflexionar sobre la exigibilidad de la responsabilidad penal y, básicamente, sobre la capacidad de culpabilidad; y amerita describir, aunque más no sea en forma sucinta, cierto recorrido histórico del concepto, su diversa conceptualización y su aplicabilidad a diferentes contextos jurídico-políticos.

Tanto el derecho romano como el derecho germánico

\footnotetext{
2 El predominio de este proyecto quedó reflejado en la fundación del Centro Argentino de Etnología Americana por parte de Marcelo Bórmida en 1973.

3 Cabe resaltar también la importante incidencia de la gestión de Monseñor Jaime Francisco De Nevares en este proceso, quien apoyó explícitamente los argumentos de la defensa.
} 
ya reconocían, en ciertas circunstancias subjetivas, la condición mitigadora o exoneradora de responsabilidad penal. Sin embargo, es más adecuado remitirse a la teoría del Derecho Natural del siglo XVII para alcanzar un contacto más próximo a las discusiones actuales en torno al concepto de inimputabilidad. Según esta perspectiva, tanto la imputabilidad como la inimputabilidad se explicaban siempre en referencia a cierta acción adjudicada a un sujeto (imputabilidad objetiva); y no así al sujeto en sí, aislado de sus circunstancias (Martínez Garay 2005). El basamento de dicha imputación era discutido alrededor del principio de "libre voluntad del hombre" en el cual se creía férreamente, de modo que cualquier acción en donde esa "libertad" estuviera condicionada se consideraba no pasible de imputación. Así, entre las causas de supresión de la imputación se contaban estados tales como el error, la coacción, la necesidad y cualquier otra circunstancia que impidiera el libre ejercicio de la voluntad. Pero no es hasta el siglo siguiente que el derecho toma estos argumentos y los convierte progresivamente en categorías jurídico-penales, introduciéndolos como causas de exculpación o mitigación de la pena, exclusión de intencionalidad y ausencia de dolo (Martinez Garay 2005).

Hacia la segunda mitad del siglo XIX se produce un quiebre profundo en la consideración de la imputación: su traslado hacia una forma subjetiva. En el surgimiento de esta consideración la aparición de la idea de "individuo" y la revalorización de éste como sujeto de derecho funcionó como bagaje conceptual fundamental. Los estudiosos del derecho apoyados en la idea de que la ley constituía el espacio de racionalidad por excelencia, propugnaron una estrecha oposición entre los comportamientos violentos y las nuevas maneras de subjetividades esperadas, acordes a la implementación de modernas formas de poder político (Martinez Garay 2005).

Por otro lado, el fortalecimiento de la psiquiatría como ciencia secularizada acompañó de igual forma la subjetivación de la inimputabilidad. Al ampliarse el conocimiento sobre las enfermedades mentales, se amplió también el espectro respecto de los sujetos que podían padecerlas y se instaló la discusión en relación a qué hacer con este nuevo grupo de sujetos "inimputables" que aparecía en escena (Hegglin 2006).

En los plexos normativos penales contemporáneos de occidente, esta tensión histórica entre dos formas de abordar la imputación (objetiva y subjetiva), ha dejado su impronta. Si bien dichos corpus suelen aceptar que la inimputabilidad se establece respecto al sujeto pero siempre en relación a un acontecimiento en concreto, no es extraño encontrar en la jurisprudencia, alusiones a la inimputabilidad como una "incapacidad general de actuar de acuerdo a la norma" atribuible a determinados sujetos.

\section{El Código Penal Argentino (CPA) vigente ${ }^{4}$ incorpora su}

\footnotetext{
${ }^{4}$ Los primeros antecedentes en materia de inimputabilidad y medidas
}

perspectiva respecto a la inimputabilidad en el Artículo 34, inciso 1:

\begin{abstract}
“No son punibles: $1^{\circ}$. el que no haya podido en el momento del hecho, ya sea por insuficiencia de sus facultades, por alteraciones morbosas de las mismas o por su estado de inconsciencia, error o ignorancia de hecho no imputable, comprender la criminalidad del acto o dirigir sus acciones.

En caso de enajenación, el tribunal podrá ordenar la reclusión del agente en un manicomio, del que no saldrá sino por resolución judicial, con audiencia del ministerio público y previo dictamen de peritos que declaren desaparecido el peligro de que el enfermo se dañe a sí mismo o a los demás. En los demás casos en que se absolviere a un procesado por las causales del presente inciso, el tribunal ordenará la reclusión del mismo en un establecimiento adecuado hasta que se comprobase la desaparición de las condiciones que le hicieren peligroso."
\end{abstract}

En primer lugar me interesa resaltar que la fórmula expresada en el código propone lo que la ciencia del derecho denomina propuesta "mixta"; refiriéndose a la combinación de causas psiquiátricas (insuficiencia de facultades mentales, alteraciones morbosas o estado de inconsciencia) con consecuencias psicológicas (comprender la criminalidad del acto o dirigir sus acciones) consideradas para la determinación de inimputabilidad. Sin embargo, la interpretación judicial de este artículo en

de seguridad en el derecho penal argentino, pueden rastrearse en el Código Tejedor (P.1 ${ }^{a}$, L.II, tít. III, art.2 inc. $2^{\circ}, 3^{\circ}$ y $5^{\circ} ; \mathrm{N}^{\circ} 147$ de Bs.As.), donde son contemplados los casos de incapacidad psíquica y se avanza inclusive sobre la categoría de "semiimputables" (en relación a la "debilidad natural de la inteligencia") (De La Rúa 1972). El proyecto de Código Penal de Villegas, Ugarriza y García de 1881 (art.93, inc. $3^{\circ}$ ) modificó esta consideración ofreciendo un acercamiento a la inimputabilidad definida biológicamente y disponiendo que dichas personas, en el caso de cometer hechos en perjuicio de terceros, habrían de ser encerradas en alguna de las casas destinadas a los de su clase o podrán ser entregados a sus familias para sus cuidados, sin perjuicio de la cooperación y vigilancia de la autoridad (art.95) (Bisquet 2008). Hacia 1886 un nuevo proyecto de Código Penal, consagra la regla de impunidad para el inimputable (art.81, inc. $1^{\circ}$ ) integrando en su consideración, tanto la falta de capacidad como la falta de conciencia (Diaz 1926). Posteriormente, hacia 1891 nace un nuevo proyecto de Código Penal donde se profundiza el basamento biológico de la inimputabilidad y liga su consideración a enfermedades y trastornos mentales fundados en la psiquiatría de la época (art.59) (De la Rua 1972). Siguiendo la orientación de éste último, el proyecto de Código Penal de 1906 asigna una particular amplitud a la fórmula de inimputabilidad (art.41) y establece un nuevo sistema de medidas de seguridad: "En caso de enfermedad mental, el juez ordenará la reclusión del agente en un manicomio, del que no saldrá sino por resolución judicial, con audiencia del ministerio público y previo dictamen de peritos que declaren desaparecido el peligro de que el enfermo se dañe asimismo o a los demás (art.41, inc. $1^{\circ}$ ). El proyecto de 1917 convertido en Código Penal en 1921, acoge las críticas de las obras de Julio Herrera, quien recuperando la fórmula del Código Ruso expresada en su artículo 35, rechaza la semiimputabilidad y corre la discusión exclusiva de la inimputabilidad en términos de enfermedad mental; instalando el texto normativo actualmente vigente (Bisquet 2008). 
el ámbito nacional, ha estado frecuentemente reducida al método psiquiátrico ${ }^{5}$.

Así, la emocionalidad subjetiva de la persona al momento de la imputación incorporada en el derecho argentino, es considerada casi exclusivamente como un estado psíquico del individuo; caracterizado como súbito, breve, intenso y que genera en el sujeto cierta superación de las "situaciones normales del espíritu" (Levene 1977). Las emociones abordadas desde esta perspectiva se ven ligadas prácticamente al ámbito de lo irracional y dejan de lado las ataduras que las relacionan al pensamiento; ya que ignoran la intervención de ideologías acerca de personas y cosas que importan en el proceso emotivo y desestiman el aspecto de la fórmula mixta que incorpora la valoración extra biologicista de la conducta (Nussbaum 2006).

Por otro lado, surge de la norma que no sería suficiente la evidencia de enfermedad mental en el sujeto para la declaración de inimputabilidad, sino que debería probarse que la misma ha impedido la captación del disvalor (valor jurídico) de una conducta concreta; lo mismo ocurre con aquellos sujetos no alienados que a pesar de su "sanidad" no tuvieran conciencia de la criminalidad de sus actos por cualquier motivo o alteración circunstancial.

Ahora bien, si bien es cierto que la inimputabilidad propuesta por el código argentino conlleva en su discusión una base extra jurídica, también expresa claramente que el enjuiciamiento de la capacidad de culpabilidad no es una cuestión que corresponda resolver a la psicopatología, a la psiquiatría o a la psicología; sino que la valoración de la conducta en el caso concreto está previsto, que sea de naturaleza jurídica (Vanini, Del Cerro, Saulines 2003). Por esa misma razón esta cosmovisión del derecho, espera una actitud activa y determinante del juez en su administración; y si bien el asesoramiento de peritos respecto a la existencia de cierta realidad mental del sujeto en un momento determinado será un dato importante a tener en cuenta, la valoración jurídica de la inimputabilidad está siempre a cargo del magistrado interviniente, quien deberá considerar los alcances de estos estados a los efectos de exculpación (Frías Caballero 1981).

Finalmente, quisiera hacer notar que el tipo de emocionalidad contemplada en el código penal nacional es exclusivamente aquella que se presenta ligada a una acción violenta, que puede o no generar un estado de incomprensión de la criminalidad de la acción ejecutada (habilitando la declaración de inimputabilidad) pero que irremediablemente debe generar cierta rotura de los frenos inhibitorios del sujeto (consintiendo así, al

\footnotetext{
5 La gran influencia de una psiquiatría forense, con perspectiva naturalista e intelectualista, en el derecho argentino ha sido determinante en este sentido (Silva 2008). Sobre este tema en particular pueden consultarse los trabajos de Frías Caballero (1981).
}

menos, cierto reproche menor por la turbación del ánimo) (Levene 1977). De esta forma, la exculpación o la mitigación de la culpa ante actos violentos invocando la alteración emocional traen aparejado, en muchos casos, la determinación de insania de los acusados y la consecuente consideración de los mismos como sujetos disminuidos en sus aspectos cognoscitivos y valorativos.

Reconociendo el poder nominador que adquiere el derecho, tan capaz no sólo de regular sino también de crear y de dar estatus de realidad a las decisiones y enunciaciones que promueve, se hace relevante un análisis profundo de la construcción de los discursos jurídicos de inimputabilidad y sus efectos.

\section{La construcción jurídica de la inimputabilidad}

\section{Algunas consideraciones metodológicas}

Entiendo que el expediente judicial es un objeto donde se concretan los efectos de la relación entre institución, conflictos y actores, y que dicha vinculación no se desarrolla de forma directa, sino que es mediatizada tanto por la escritura como por la acción de los funcionarios intervinientes (Martinez 2004).

Desde esta perspectiva, la declaración de inimputabilidad no puede abordarse como un episodio puntual y definitivo del acto jurídico, sino que debe ser analizada como una consideración a la cual se accede a través de una construcción discursiva específica. Desarmando el proceso narrativo del expediente, se hace posible observar la intervención de una multiplicidad de voces y argumentos que cooperan, negocian y/o se resisten entre sí; permitiendo ponderar cómo a través de esta dinámica, se elabora un relato sobre los hechos acontecidos, se despliega cierta explicación de lo ocurrido, se detallan las razones que indujeron a cometer la ofensa bajo análisis $y$, finalmente, se reconoce la ausencia de delito.

En este sentido, el marco teórico y metodológico aportado por el Análisis Crítico del Discurso puede hacer grandes contribuciones al abordaje del expediente judicial. Este enfoque interdisciplinar, se sustenta sobre la idea de que existen reales y eficaces vinculaciones entre el discurso y la estructura social en general, y con la desigualdad social en particular. De esta forma, el acceso y el control sobre determinadas formas de discurso, se constituyen en recursos específicos del poder. Aquellos grupos de la sociedad que pueden controlar los discursos más influyentes, serían aquellos que tienen también más posibilidades de controlar las mentes y las acciones de los otros (Van Dijk1999).

Propongo entonces, el abordaje del material del caso a través del análisis y la interpretación de los distintos indicadores significativos y los diversos criterios que posibilitan su construcción como discurso. Prestando 
especial atención a las estrategias de negociación que despliegan los distintos textos del expediente, a la descripción de los medios con los que logran aceptación y credibilidad, a su posibles contradicciones y a la identificación de los elementos que no expresan u omiten en su argumentación.

\section{La construcción jurídica de la inimputabilidad en el caso de Lonco Luán}

El primer texto dentro del expediente que construye un relato acerca de lo sucedido es el que surge de la declaración de los propios acusados; y aunque sus dichos no conforman una narración homogénea (de hecho casi todos describen los detalles de lo acontecido de forma bastante distinta), hay algunos elementos que a mi criterio, los unifican como discurso constructor de sentido. Todos coinciden en que los acontecimientos se originan cuando una de las mujeres de la comunidad se siente indispuesta, y que por cuestiones climáticas les era imposible sacarla de Lonco Luán para su atención médica; que fue entonces cuando la propia enferma propone una sesión de sanación colectiva. Que estuvieron dos días ayunando y sin dormir y que en algún momento del desarrollo del ritual llegan a la conclusión de que la mujer enferma estaba endemoniada (aunque no hay coincidencia en las distintas declaraciones sobre quién llega a esa idea ni sobre cuándo lo hace):

"La hermana Sara se transformó en culebrón y la había tomado el demonio la forma, la veíamos como era ella,

pero ya no era gente porque andaba de rodillas." Declaración indagatoria de un acusado

Cuentan que entonces empiezan a patearla para sacarle el espíritu maligno hasta matarla; y que al morir la mujer, observaron cómo el demonio salía de su cuerpo y se apoderaba de otros cuerpos más débiles (el de los niños). Relatan que increpan entonces a los niños para inducirlos a vomitar y a liberarse voluntariamente del diablo; y que al no obtener respuesta alguna comienzan a golpearlos. Todos explican que la desesperación por retirar al diablo de los cuerpos, se debía al convencimiento de que si no lo hacían, el espíritu tomaría dominio de la comunidad destruyéndola:

"El demonio sale de un cuerpo y entra en otro más débil. (...)

Prefiero que muera uno y no perder a todo el pueblo.

Hay que sacar al demonio para que sane."

Declaración indagatoria de un acusado

“Porque el espíritu maligno a nosotros no nos dejaba llegar al...

íbamos a favor del demonio. Efectivamente fuimos triunfadores nosotros, porque sino estaríamos todos muertos, así como le dije, quedan todos locos,

como una cosa de esas.

Yo creo que los que se murieron se salvaron, porque murieron por Dios."

Declaración ante el juez de un acusado

Analizando estas declaraciones podríamos concluir que los acusados no comparten - ya sea en todo o en parte - la materia de la prohibición jurídica en sentido estricto. Si bien expresan conocer que han cometido un delito y reconocen la diferencia entre la legalidad e ilegalidad según lo prescribe la ley del estado nacional, se deja entrever el desconocimiento de la pertinencia de estas normas para la propia vida y fundamentalmente para la situación particular bajo resolución. Se reconoce la vigencia de la norma en sentido abstracto, aunque en la circunstancia concreta de la matanza esas normas parecen haber perdido sentido:

\footnotetext{
"Dios dice que no hay que matar, hicimos esa cosa pero no lo hicimos contentos, sino fue en contra (...) había que darles sanidad. La autoridad a mí no me cree que hay espíritu maligno, sería un

gran avance para nosotros que si un pastor explicara cómo

es el Maligno..."

Declaración indagatoria de un acusado
}

Ahora bien, si la captación del disvalor de la conducta concreta que, normativamente es factor de inimputabilidad, estaría aparentemente cumplimentada, sólo lo está en un sentido distinto al previsto. La incomprensión de la criminalidad del hecho cometido en este caso no estaría vinculada al ámbito de lo mental en términos psicopatológicos, sino más bien a valoraciones y factores culturales que habrían intervenido en la toma de decisiones de los sujetos al momento de cometer el hecho. Esta cuestión genera una inquietante tensión con aquella lectura tradicional y arraigada de base biologicista del artículo 34 del CPA a la cual me refería más arriba, que será reflejada fundamentalmente en el discurso pericial del expediente.

Los informes de profesionales (firmados por psiquiatras y psicólogos en su gran mayoría) que se despliegan a lo largo del caso, desarrollan una multiplicidad de acercamientos y explicaciones a los hechos. Mientras algunos prestan más atención a identificar las características y el estado de situación de los individuos y/o el grupo en general, otros se dedican principalmente a relatar en detalle la reconstrucción del hecho acontecido y sus posibles explicaciones. Aún así, hay al menos un elemento que permite analizarlos como una única argumentación dentro del expediente. A pesar de que la valoración de imputabilidad es para el derecho, una atribución jurídica según fue desarrollado más arriba, llamativamente son 
los propios peritos quienes ofrecen en el expediente la consideración sobre la imputabilidad de la culpa; obteniendo como resultado inmediato el desplazamiento del nivel de consideración de la transgresión
“En forma retrospectiva podemos inferir que en el momento
de cometer el ilícito que se investiga, se encontraban en un trance
de naturaleza mística colectiva (éxtasis) que los haría estar comprendidos
dentro de lo considerado por el CP (art.34, inc. 1)" Informe de peritaje
"Se ha establecido que los actos que dan lugar a este peritaje pueden
haber sido realizados en la situación del mencionado art. 34"
Informe de peritaje

Al desarrollar la evaluación de la infracción respecto de parámetros fisiológicos, psiquiátricos o psicológicos, estos discursos inscriben la criminalidad en un ámbito completamente ajeno a la ley. Ello trae aparejado una consecuencia inmediata, la consideración de la infracción ya no simplemente como un acto delictivo, sino como una conducta asociada a cierto rasgo individual del transgresor: ". . permite pasar del acto a la conducta, del delito a la manera de ser..." (Foucault: 1999:29)

Posteriormente y casi sin mediación alguna en el expediente de Lonco Luán, esas características "criminales" del agresor, son atribuidas al grupo étnico en su totalidad y se tornan cada vez más, consideraciones de tipo moral:

"Viven en estado de completa ignorancia, extrema pobreza,

donde los valores y normas morales no tienen ninguna validez,

conduciendo al degeneramiento en sí como personas, con los consecuentes trastornos psicofísicos y sociales." Informe de peritaje

“Debe prevenirse el daño intraétnico que significa la situación

de peligrosidad de la etnía de la cual se han producido los acontecimientos".

Informe de peritaje

Así, el expediente construye la inimputabilidad de los acusados en términos básicamente subjetivos; operando a la vez, un importante forzamiento interpretativo con el fin de resaltar la injerencia de factores culturales, en su determinación:

"Han sufrido una inversión en el juicio valoratorio de las cosas, con total confusión (...) entre lo que es el bien y lo que es el mal. Creándose así

un estado crepuscular de consciencia. La imputabilidad que es la capacidad de ser culpable constituye una capacidad subjetiva."

Alegato abogado defensor

La sentencia del magistrado termina por reforzar este deslizamiento semántico entre lo individual y lo cultural:

"Como bien lo señala el Dr. P en el dictamen que se considera, no se trata de la peligrosidad de un individuo,

sino de un grupo como tal; peligrosidad que nace de la situación en que desarrollan sus vidas y sus propias características."

Considerandos de la sentencia del juez Simonelli

Establece además la falta de intencionalidad y fundamentalmente la ausencia de claridad para observar lo relevante en la situación particular por parte de los acusados, considerando la inimputabilidad de todos los implicados y ordenando su internación:
"... los procesados (...) no pudieron comprender la criminalidad
del acto ni dirigir sus acciones por encontrarse en un
estado de éxtasis profundo al momento de ocurrir los sucesos de autos."
Considerandos de la sentencia del juez

\section{Deber jurídico, castigo y perdón}

La teoría pura del derecho sostiene que existe un deber jurídico sólo si una norma de derecho impone una sanción - en términos de acto de fuerza administrado por algún órgano de la comunidad- a determinado comportamiento humano; y que por ende el "delito" se define simplemente como aquel acto contra el cual reaccionaría la sanción: "Existe, en efecto, identidad entre la proposición que afirma que un individuo está jurídicamente obligado a hacer el servicio militar y la que dice que debe ser castigado si no lo cumple." (Kelsen 1959:30). La norma se establece así como un verdadero esquema de interpretación y todo problema relacionado con el derecho adquiere un matiz intrínsecamente normativo, desestimando el peso que la complejidad del fenómeno social posee en su desarrollo y determinación.

Durkheim (2007) en cambio se refiere al "crimen" específicamente como un acto que ofende determinados sentimientos colectivos dotados de una energía y claridad particulares, sobre los cuales se estructura toda sociedad. Por ende, cuando se castiga una transgresión lo que realmente se juzga es la ofensa a esos principios morales "sagrados" y trascendentes. Porque es justamente a través de un sistema de sanciones y prohibiciones, que 
la sociedad se produce como tal (en términos de orden simbólico), y es así también como define jerarquías y asigna roles hacia su interior.

Marx también se ha referido a estas cuestiones asegurando que en realidad "...el criminal estimula las fuerzas productivas" (1945:217). Y esto en dos sentidos: por un lado produciendo crímenes y sistemas penales; pero a la vez, generando fuertes reacciones morales con su accionar que en última instancia, refuerzan la vigencia de la ideología dominante Así, el esquema delito-castigo que, a primera vista parece bastante simple y automático, se complejiza y adquiere dimensiones mucho más amplias.

El castigo y las diversas formas que adquiere la punición podrían definirse, entonces, como mecanismos de reinscripción de los límites: restablecen significados, restituyen las diferencias y afirman hegemonías en beneficio de determinado tipo de cohesión social (Tonkonoff 2007).

Por su parte, Foucault (2002) analiza rigurosamente la historicidad del castigo; y determina un cambio trascendental en su concepción a mediados del siglo XVIII. Hasta esa fecha, el castigo se presentaba principalmente asociado a cierta lucha cuerpo a cuerpo entre el soberano y el condenado, ligado al suplicio y a la venganza cruel. Pero simultáneamente, bajo este antiguo régimen, se encontraban generalizados lo que el autor denomina "ilegalismos tolerados", espacios de inobservancia o exención asociados tipológicamente a diferentes estratos sociales (privilegios concedidos a distintos individuos o comunidades, consentimiento de ciertas acciones a determinados sectores, imposibilidad efectiva de imponer castigo a ciertos grupos, etc.) Lo cierto es que la existencia de estos ilegalismos formaban parte fundamental de la vida política y económica de la época. La reforma penal nace entonces de la necesidad de luchar contra un sobrepoder soberano, pero también sobre la necesidad de oficializar y expandir dichos ilegalismos previamente conquistados. De ahí que Foucault asegure que: "... hay que concebir un sistema penal como un aparato para administrar diferencialmente los ilegalismos, y no, en modo alguno, para suprimirlos a todos." (2002:93) La nueva estrategia formulada para el ejercicio del poder de castigar, no proponía entonces "castigar menos", sino "castigar mejor"; atenuaba la severidad del castigo a fin de ganar universalidad y profundidad sobre el cuerpo social.

No existen por ende, evidencias históricas ni razones lógicas para creer que el impulso del castigo sea anterior o más fuerte que el impulso a la remisión del mismo; aunque es sabido que no han tenido la misma publicidad ni se han abordado con el mismo detalle en la tradición del pensamiento occidental. De hecho, pueden rastrearse prácticas de perdón en los códigos legales más tempranos. El asesinato más antiguo de la historia, relatado en el Viejo
Testamento, la muerte de Abel en manos de su hermano Caín, no fue completamente castigado; Dios conmutó la pena del destierro al asesino permitiéndole habitar en la tierra de Nod, al este del Edén. (Dean Moore 1989)

Novitz (1998) ha reflexionado específicamente sobre la disculpa y el perdón, definiendo estos procesos como ejercicios complejos que involucran la comprensión de las acciones incorrectas desde el punto de vista del agresor en el contexto general de su propia vida; es decir que suponen cierta vinculación empática acompañada de sentimientos de compasión o misericordia como facilitadores del proceso.

Arendt (1953) en el desarrollo de su teoría política, ya le otorgaba a la "comprensión" un peso relevante como forma de reconciliación con la historia. Para la autora la "comprensión" implica juzgar los fenómenos; es decir emitir juicio, enunciar, pronunciarse. Funciona en distintos niveles que van desde formas vagas y omisas pertenecientes al ámbito del sentido común, hasta elaboraciones complejas de producción científica; pero que en cualquier caso, constituyen elementos necesarios y de retroalimentación constante. De esta forma, la "comprensión" es la que produce y sostiene la existencia misma del mundo de lo público.

Pettigrove (2007) también dedica parte de su obra a problematizar el lugar que ocupa la "comprensión" en el proceso de perdonar; poniendo en duda al mismo tiempo, que dicho proceso deba exigirle tanto más al ofendido que al ofensor, y ofrece de forma alternativa, tres modelos o esquemas que analizan estas relaciones. El primero debt cancel model - concibe al perdón como la anulación de una deuda de carácter moral; el segundo - emotional model - se refiere al perdón como una modificación en la actitud del ofendido después de ocurrida la ofensa. En ambos casos, ni la comprensión, ni el conocimiento del otro o de las condiciones en las que se ha cometido la ofensa, parecen importantes para alcanza el perdón. El tercer modelo -volitional model - describe un perdón ligado a la prevención de las cualidades peligrosas del ofensor y al compromiso con el bienestar del mismo por parte del ofendido; en este sentido el conocimiento desarrolla un rol fundamental. Atendiendo a este último modelo, es factible observar algunas coincidencias con el sentido que la letra del Código Penal Argentino le otorga a la búsqueda de factores de inimputabilidad, emoción violenta y condiciones extraordinarias de atenuación.

Griswold propone el concepto de perdón político (political forgiveness) a fin de considerar cierta diferenciación entre los procesos de perdón interpersonal y aquellos relacionados a esferas de relaciones públicas, gobernadas por un sistema político determinado y que implican generalmente elementos como el control, la influencia, el poder y la autoridad. El perdón considerado en este sentido es un acto moral, no reductible a intereses 
individuales o cálculos particulares: "Considero que una de las funciones del perdón (...) ofrecido en un contexto político es precisamente comunicar un punto moral público e impersonal." (2007:142).

Desde esta perspectiva el proceso de perdón y su aceptación adquieren formas marcadamente simbólicas y un fuerte contenido ritual: aquel que perdona no es directamente el injuriado por la ofensa cometida; tampoco se requieren necesariamente la reducción del resentimiento por parte del ofendido o el arrepentimiento del ofensor, ni se indagan los verdaderos motivos de los agentes en cuestión.

El perdón al que estoy refiriéndome en el presente artículo entonces, requiere del desprendimiento de ciertas categorías valorativas asociadas históricamente a él. Categorías que lo ligan a cierta virtud misericordiosa y divina, o bien a actos de clemencia inspirados en ella. En este sentido su uso ha sido recluido casi exclusivamente al ámbito de la religiosidad y la intersubjetividad, relegando su carácter público, y fundamentalmente su entramado político.

Este camino de deconstrucción conceptual, debe comenzar reconociendo al perdón no como un acto privado o un acto divino, sino como una actividad del ámbito público; que sólo puede ser investida por un rol social o legal ${ }^{6}$ (Dean Moore 1989). El perdón que intento construir, es además aquel que mitiga o exculpa por completo de cierto castigo a un ofensor; y que reestablece de inmediato la inocencia del mismo ante la ley. Es así un perdón básicamente performativo (en el sentido de Austin 1952); es una locución que por el simple hecho de ser pronunciada, bajo condiciones específicas, produce una acción determinada: nuevas relaciones jurídicas, pero también nuevos sentidos sociales.

\footnotetext{
6 Cabe señalar que una cantidad importante de pensadores han hecho referencia al "perdón" en este sentido; autores como Hanna Arendt (2003) o Paul Ricouer (2000) han trabajado en profundidad alrededor de este concepto específicamente en los procesos europeos de posguerra y han analizado minuciosamente sus posibles alcances en esos contextos. Otra cantidad de pensadores lo han abordado al reflexionar sobre las políticas de "reconciliación" ligadas a la transición del Apartheid al estado democrático en Sudáfrica (ver: Griswold, C. 2007). También se ha escrito ampliamente en esta misma línea sobre los indultos presidenciales a represores de las dictaduras militares del siglo XX en Latinoamérica y las políticas de impunidad (ver: Ames, R. 2005; Anxo García, M. 1993; Dulitsky, A. 1996; Espinoza Cuevas, V., Ortiz, M.L., Rojas, P. 2003; Garretón, M. 2001; Lira, E. 1994; Mack, H. 2005; Zaffaroni, E. 2001); como así también sobre planes y políticas de seguridad vinculados al control de grupos alzados en armas y guerrillas en centroamérica (ver: Plata Pineda, O. 2009). Pero todos estos procesos que ponen en juego "derechos de gracia", suponen un monarca absoluto que invistiendo cierto atributo cuasi divino, practica en nombre del Estado un "perdón" que trasciende y neutraliza el derecho (Derrida 2003). El "perdón" al que hago referencia a lo largo del artículo en cambio, se establece en la norma misma, es ejecutado por operadores de justicia y se desenvuelve específicamente en el ámbito judicial; por tanto le incumbe específicamente al derecho. Una profundización en el análisis comparativo de estos "perdones" públicos podrían motivar el desarrollo de otro artículo, pero no es lo que nos ocupa aquí.
}

Desde estas consideraciones, creo factible abordar el discurso jurídico de la inimputabilidad (expresado normativamente en el art. 34 inc. 1 del CPA y reinterpretado en cada resolución administrativo - judicial que alude a él) como una práctica institucionalizada y codificada de perdón.

\section{El poder de perdonar}

Los efectos y alcances de la aplicación y el ejercicio de prácticas de perdón, han sido también ampliamente discutidos a lo largo de la historia.

En uno de sus extremos emergió lo que se denominó Modelo Utilitarista del castigo, representado por autores como Bentham (2010) o Beccaria (1983); quienes sustentados en el principio de que la ley y las instituciones judiciales deberían servir al bien público, defendieron al perdón en todas aquellas circunstancias en las cuales su aplicación, provocara menos daño a la sociedad que la aplicación de un castigo. Así, cuando el castigo no es eficaz, cuando no es necesario o cuando es demasiado costoso, no debería echarse mano a él y el perdón estaría suficientemente justificado. Este modelo, provee a la punición de una herramienta económica de prevención fundamentalmente semiotécnica7: "Hay que castigar exactamente lo bastante para impedir." (Foucault 2002:98); convirtiendo así el campo de la penalidad en un arte de los efectos, donde el castigo será sólo una parte del arsenal de recursos a su disposición.

En respuesta a este modelo, Kant fue uno de los primeros autores que observó los vínculos estrechos existentes entre el castigo y el perdón; y denunció muy tempranamente los efectos negativos y las formas coercitivas que, en muchos casos, acompañaban a las prácticas "tolerantes". Se delineaba así el modelo retributivo, que promueve la idea de un castigo ligado directamente a la transgresión cometida y no a posibles transgresiones; según esta propuesta el castigo debería ser directamente proporcional a la falta acontecida (Dean Moore 1989).

En crítica a ambos modelos, Hegel (1968) escribe su Filosofía del Derecho. En esta obra, el autor se distancia del modelo retributivo por considerar insostenible su premisa central, que supone necesariamente la existencia de cierta escala natural por la que a cada crimen le correspondería un castigo natural. Pero fundamentalmente se alza contra las interpretaciones utilitaristas, esgrimiendo toda una serie de razones en contra de las prácticas de perdón; señalando que las mismas violan el derecho que pertenece a todo criminal: el derecho a ser castigado.

\footnotetext{
7 El concepto de semiotéctica es utilizado por Foucault para referirse a la forma que adquiere la administración de ilegalismos a partir de la reforma penal del siglo XVIII, caracterizada por la utilización de técnicas destinadas a producir signos dirigidos a un cuerpo social, donde la representación del castigo y la prevención adquieren un lugar preponderante.
} 
En esta misma línea Barker escribió: "Si respetamos la responsabilidad, debemos respetar el derecho de los ofensores a ser castigados por sus ofensas." (1951:1979) Según esta lógica, un acto criminal es el resultado directo de una elección, una decisión conciente de un sujeto que deber ser respetado como una entidad racional y libre. El perdón, en este sentido, desoye y niega el derecho del transgresor, a ser tratado como persona; lo despoja de humanidad condenándolo a la animalidad o en el mejor de los casos, al lugar más relegado del espectro social. Considero que es justamente así como el perdón, se transforma en "poder de perdonar".

La antropología permitió conocer con certeza la existencia de prácticas - ampliamente extendidas en pueblos no occidentales documentados etnográficamente - ligadas a la desvalorización y desestimación dable a través de experiencias rituales, ceremoniales e inclusive cotidianas (como la burla, el rumor o la broma) de todo efecto de poder no deseado y de todo aquel que pretendiera arrogárselo. Clastres ha analizado por ejemplo, toda una serie de mecanismos implementados por los indígenas Yanomani a fin de mantener a sus guerreros prestigiosos, lejos de la posibilidad de detentar algo más que prestigio social (Clastres 1980) Sin embargo, poco se ha reparado dentro de la disciplina, en el ejercicio de dispositivos similares en nuestras sociedades modernas.

El poder de perdonar descalifica definitivamente al ofensor como ciudadano y le adjudica características monstruosas, generalmente vinculadas a la locura y la anormalidad; mecanismo que en sociedades como la nuestra, no hace más que desacreditar la transgresión como alternativa racional; pero fundamentalmente reconfirma la existencia de "espacios de acceso restringido" en los términos ofrecidos por Van Dijk: "... los grupos tienen (más o menos) poder si son capaces de controlar (más o menos), en su propio interés, los actos y las mentes de los (miembros de) otros grupos. Esta habilidad presupone un poder básico consistente en el acceso privilegiado a recursos sociales escasos, tales como la fuerza, el dinero, el estatus, la fama, el conocimiento, la información, la «cultura», o incluso varias formas del discurso público y de la comunicación. Hallamos de entrada entonces, en nuestro análisis de las relaciones entre el discurso y el poder, que el acceso a formas específicas de discurso (...) es en sí mismo un recurso de poder" (Van Dijk 1999:185).

\section{La eficacia del perdón en Lonco Luán}

El expediente de Lonco Luán deja constancia de que los imputados expresaron en forma concluyente los hechos que recordaban; y explicita las razones aludidas por ellos y las circunstancias que los incitaron a llevar adelante los actos bajo juzgamiento. La violencia ejercida en Lonco Luán según se explicita en los dichos de los imputados, funcionó como un verdadero acto de sanidad y purificación social. Kalinsky ha profundizado en estas cuestiones, destacando que: "El homicidio por brujería [entre los mapuche] es valorado en tanto se conserva la armonía social y el bienestar general. Es una forma de control social de orden cultural y por ende sometida a los vaivenes históricos de la dinámica del cambio social" (2000:193).

Sin embargo, la narrativa del perdón relega estos dichos al vacío, haciendo prevalecer a lo largo del expediente, aquellas argumentaciones que de forma expresa niegan las afirmaciones y reconocimientos de los propios acusados. Así, incorpora una descripción de los hechos acontecidos en términos de "verdad" objetiva, aportados al expediente principalmente por los discursos periciales; luego, a través de la sentencia del juez interviniente y otros discursos de funcionarios judiciales, identifica de forma expresa y clara la falta cometida, individualiza a quienes han sido perjudicados $u$ ofendidos por esta acción y establece el pronunciamiento de un perdón público construido a partir de la enajenación de aquello que los mismos acusados aceptan (Kalinsky 2000). En este sentido, el discurso de inimputabilidad construido en el expediente de Lonco Luán, puede ser leído como un discurso "grotesco" (en sentido foucaultiano); y como tal ligado a la indignidad del poder, a ese mecanismo que tiene por efecto la manifestación de su inevitabilidad y la imposibilidad de eludirlo (Foucault 2000).

Benjamin asegura que toda violencia es poder que conserva derecho, pero a la vez considera que la misma contiene un importante potencial creador de nuevo derecho (nuevo orden). Así "... el interés del derecho por monopolizar la violencia respecto a la persona aislada no [...] (tiene) como explicación la intención de salvaguardar fines jurídicos, sino de salvaguardar el derecho mismo. (...) la violencia, cuando no se halla en posesión del derecho a la razón existente, representa para éste una amenaza, no a causa de los fines que la violencia persigue, sino por su simple existencia por fuera del derecho." (Benjamin 1991:4)

Nuestro sistema penal ante una acción antijurídica puede optar y poner en juego fundamentos de distinta naturaleza; por un lado puede establecer penas como respuestas a una responsabilidad entendida como reproche, o bien estipular medidas de seguridad de alcance tutelar como resultado de cierta responsabilidad social (peligrosidad). En Lonco Luan:

\footnotetext{
“... disponer la internación de los nombrados en un instituto

especializado, hasta tanto desaparezcan las causales de peligrosidad."

Resolución de la sentencia del juez
}

Cabe señalar que en la aplicación de las penas los sujetos cuentan con una serie de garantías de las que 
carecen en la aplicación de las medidas de seguridad: "... [la inimputabilidad] a través de su apariencia de concepto científico, justifica racional y emocionalmente un mecanismo de control social (...) pero sin las garantías propias de la [pena], lo cual hace que las posibilidades de intervención sobre el individuo sean todavía mayores" (Sotomayor Acosta 1990:9).

Desde esta perspectiva, la aplicación de un perdón institucional basado en una declaración de inimputabilidad subjetiva sobre un grupo social en particular (como he argumentado anteriormente), podría analizarse como una estrategia estatal de negación de la violencia transgresora altamente eficaz, como un recurso de ocultamiento del sentido de su ejecución y por ende, como forma efectiva de anulación de su carácter productor de orden social; que da como resultado la inmediata restitución del orden amenazado.

Al mismo tiempo, esta argumentación consigue la descalificación y la exclusión del grupo en cuestión:

“...el indígena es un agente de responsabilidad disminuida, al cual la aplicación de la norma debe hacérsele con el sentido y alcance tutelar que

su malograda condición humana exige.(...) Sus creencias, sus misterios,

sus fobias, sus pánicos lo hunden sin remedio en la irrealidad de sus formas."

Pedido de la defensa Dr. Bruce

Es interesante detenerse a analizar esta solicitud del defensor, respecto al carácter tutelar con el cual debería aplicarse la norma sobre el indígena. Vale recordar que las estrategias tutelares como políticas de Estado, surgen hacia mediados del siglo XIX en los países europeos industrializados; no tanto para neutralizar la condición social de pobreza sobre la que comenzaba a asentarse la formación del excedente capitalista, sino fundamentalmente para dirigir moralmente la organización de la vida material de la clase obrera, como también para corregir aquellas conductas sociales "desviadas" caracterizadas jurídicamente como de "situación irregular" (Dasso 2004).

En Argentina, las políticas tutelares ocuparon un papel primordial durante el proceso de construcción del Estado nacional, tanto en la búsqueda de integración de la inmigración proveniente de Europa como en el establecimiento de los regímenes de acumulación agroexportadores (Di Tella 1967).

En la década del 70 surgen en nuestro país las políticas de "desarrollo de la comunidad", como parte de una política más amplia de contenido tutelar impulsada por el Banco Mundial. Estas políticas ya se habían institucionalizado regionalmente unos años antes con el "Acta de Bogotá" (1960); y luego son ratificadas en la "Carta de Punta del Este" (1961) firmada por todos los países latinoamericanos (excepto Cuba), los cuales se comprometían a implementar programas de desarrollo económico y social con el objetivo de lograr un crecimiento autosuficiente (Aguirre 2010).

Varios autores han estudiado el poder tutelar orientado específicamente hacia pueblos indígenas en este contexto. José Correa por ejemplo, ha analizado el Servicio de Protección del Indio (SPI) de Brasil, específicamente en relación a sus políticas desarrolladas entre 1910 y 1967. Su aporte se encuentra justamente en la explicitación de los procesos de incorporación de los indígenas a la "cultura nacional" por medio de los recursos pedagógicos, pacificadores e integradores de la tutela ejercida en las prácticas del SPI durante ese período (Souza Lima 2010).

Desde este marco de referencia, la eficacia del discurso de inimputabilidad construido en el expediente de Lonco Luán, puede ser entendida con mayor claridad. Al atribuirle al ofensor habilidades tan sustancialmente reducidas que hacen que no pueda ser responsable por la ofensa, lo constituyen como humano incompleto impidiendo que sea tenido en cuenta como igual en el proceso de estructuración social. Como relata Escolar, los pueblos indígenas se han constituido progresivamente asociados a cierta negatividad respecto del nuevo orden político y social en el proceso de conformación de los estados nacionales; construcción que ha ido posibilitando el ejercicio de la excepcionalidad soberana: "Lo indio funciona entonces como un monumento biopolítico del necesario polo de exclusión que sostiene la inclusión" (Escolar 2003:18).

\section{Consideraciones finales}

Según Radcliffe Brown (1968) las sanciones organizadas se definen como aquellos procedimientos definitivos, regulados y reconocidos que se dirigen hacia las personas cuyo comportamiento es socialmente desaprobado o rechazado.

Habiendo mostrado en el análisis de un caso en particular, cómo las estrategias de perdón dirigen su atención a la reafirmación implícita o explícita de determinadas normas morales, cómo exponen públicamente la confiabilidad de esas afirmaciones, cómo restituyen el sentido social, cómo (re) ubican nuevamente al ofensor bajo el halo de las normas establecidas y cómo le asignan un lugar determinado dentro de la estructura; considero que las estrategias de perdón en el expediente de Lonco Luan, otorgaron una mayor eficacia normalizadora que aquella que podría haber generado el castigo; ya que refieren mucho más al contexto de existencia, de vida, de disciplina del individuo que al acto cometido (Foucault 1999).

Será relevante en adelante atender el carácter activo 
y preponderante de estas estrategias punitivas, reconociendo su real dimensión histórica y social.

\section{Bibliografía}

Buenos Aires, 20 de junio de 2010

Aguirre, O. 2010. "La Alianza para el Progreso y la promoción del desarrollo en América Latina" en Revista Afuera Estudios de Critica Cultural, Año 5 N 9. Disponible en http://www.revistaafuera.com/articulo.php?id=110

Ames, R. 2005. “Violencia, verdad, ¿Reconciliación en el Perú? en IIDH, IDEA, Verdad, justicia y reparación. Desafíos para la democracia y la convivencia social. IIDH, IDEA, 205-227, San José.

Anxo García, M. 1993, "De las dictaduras a las democracias liberales: procesos psicosociales para la construcción del olvido". Ponencia. Santiago: XXIII Congreso de la Sociedad Interamericana de Psicología.

Arendt, H. 1953. Understanding and politics (The difficulties of understanding). Partisam Review, $\mathrm{N}^{\circ} \mathrm{XX}$.

Arendt, H. 2003. Responsability and judgment. Schocken Books, New York.

Austin, J. L. 1982. Cómo Hacer Cosas con Palabras, Paidos, Barcelona.

Barker, E. 1951. Principles of social and political thought, Clarendon Press, Oxford.

Beccaria, C. 1983. De los delitos y las penas, Bruguera, Barcelona.

Benjamin, W. 1991. Para una crítica de la violencia y otros ensayos, Iluminaciones IV, Taurus, Madrid.

Bentham, J. 2010 Introducción a los principios de la moral y de la legislación. Disponible en versión web http:// www.alcoberro.info/planes/bentham.htm [Revisado el 18-10 2010].

Bisquert, S. 2008 “El enajenado mental en la historia del derecho argentino. La respuesta penal y su evolución a través de los años" en Revista electrónica Derecho Penal Online [en línea]. Disponible en: http://www. derechopenalonline.com

Clastres, P. 1980. Investigaciones en la antropología política. Gedisa, Barcelona.

D’antonio, D. 2008. "Represión y resistencia en las cárceles de la última dictadura militar argentina" en Revista del CCC, $N^{\circ}$ 2. Disponible : http://www.centrocultural.coop/ revista/articulo
Dasso, C. 2004. "El estado de bienestar en Argentina y la burocratización autoritaria del estado de bienestar" En Revista Hologramática, Año I N¹, F.Cs.Ss.U.N. Lomas de Zamora. Disponible en: www.unlz.edu.ar/sociales/ hologramatica/hologramatica1_pp48-83.pdf

De La Rua, J. 1972. Codigo Penal Argentino. Parte General. Ediciones Lerner, Córdoba.

Dean Moore, K. 1989. Pardons. Justice, mercy and the public interest. Oxford University Press, New York.

Di Tella G. y Zymelman M., 1967. Las etapas de desarrollo económico argentino. EUDEBA, Buenos Aires.

Diaz, E. 1926. "Internamiento de Seguridad. Artículo 34 del Código Penal" en Revista Penal Argentina, Buenos Aires.

Dulitsky, A. 1996. "Las amnistías en el Derecho Internacional de los Derechos Humanos" en Fundación Mirna Mack, Amnistía y reconciliación nacional: encontrando el camino de la justicia. F y G Editores, Guatemala.

Durkheim, E. 2007. Las reglas del método sociológico. Losada, Buenos Aires.

Escolar, D. 2003. “Guerra, identidad e incorporación estatal: interpelaciones huarpe y construcción de soberanía en la autoetnografía provincial de Domingo Faustino Sarmiento" Ponencia presentada en las IX Jornadas Interescuelas/Departamentos de Historia, Córdoba 24 al 26 de septiembre.

Espinoza Cuevas, V., Ortiz, M.L. y Rojas, P. 2003. Comisiones de la Verdad: ¿Un camino incierto? Estudio comparativo de comisiones de la verdad en Argentina, Chile, El Salvador, Guatemala y Sudáfrica desde las victimas y las organizaciones de derechos humanos, Santiago: Corporación y promoción de los derechos del Pueblo (CODEPU).

Foerster, R. 1993. Introducción a la religiosidad mapuche. Editorial Universitaria, Santiago de Chile.

Foucault, M. 1999. Los anormales. Fondo de Cultura Económica, Buenos Aires.

Foucault, M. 2002. Vigilar y castigar. Nacimiento de la prisión. Siglo XXI, México.

Frías Caballero, J. 1981. Inimputabilidad penal. Capacidad personal de reprochabilidad ético-social. Ediar, Buenos Aires.

Garretón, M. 2001. “Memoria, olvido, reconciliación y 
justicia en el caso chileno" en Méndez, J., Abregó, M, Mariezcurrena, J. 2001. Verdad y Justicia. Homenaje a Emilio F. Mignone. IIDH, CELS.

Griswold, C. 2007. Forgiveness. A Philosophical Exploration. Cambridge University Press, New York.

Hegel, G. 1968 Filosofía del derecho. Claridad, Buenos Aires.

Hegglin, M. 2006. Los enfermos mentales en el derecho penal. Constradicciones y falencias del sistema de medidas de seguridad. Editores del Puero Colección Tesis Doctoral, Buenos Aires.

Kalinsky, B. 2000. Justicia, cultura y derecho penal. Ad Hoc, Buenos Aires.

Kalinsky , B.y Cañete, O. 2000. "Caminos sinuosos: el delito en zona de frontera en el sur del Neuquen" Ponencia presentada en las 1 ras. Jornadas de Historia del Delito en la Patagonia, Facultad de Derecho y Ciencias Sociales de la Universidad Nacional del Comahue.

Kelsen, H. 1959. Teoría pura del derecho. Eudeba, Buenos Aires.

Levene, R. 1977. El Delito de Homicidio. Depalma, Buenos Aires.

Lira, E. 1994. "Democracia, violación de derechos e impunidad" Cátedra Eugenio Fonseca Tortós, Universidad de Costa Rica.

Martínez, M. J. 2004. Expedientes. En Revista Oralidad y formalización de la justicia, N7.

Martínez Garay, L. 2005 La imputabilidad penal. Concepto, fundamento, naturaleza jurídica y elementos. Tirant, Valencia.

Marx, K. 1945. Historia crítica de la teoría de la plusvalía, Tomo I Volumen 3, Fondo de Cultura Económica, México.

Novitz, D. 1998. Forgiveness and Self-Respect. Philosophy and Phenomenological Research, LVIII 2.
Nussbaum, M. 2006. El ocultamiento de lo humano. Repugnancia, vergüenza y ley. Ed. Katz, Buenos Aires.

Pettigrove, G. 2007. Understanding, excusing, forgivng. Philosophy and Phenomenological Reserch VOL.LXXIV 1.

Radcliffe-Brown, A. 1968. Estructura y función de la sociedad primitiva. Anagrama, Barcelona.

Radovich, J.C. 1983. "El pentecostalismo entre los mapuches de Neuquén" en Relaciones de la Sociedad Argentina de Antropología, T. XV, Buenos Aires.

Ricoeur, P. 2000. La memoria, la historia, el olvido. Fondo de Cultura Económica, Buenos Aires.

Silva, D., Mercurio, E. y López, F. 2008. Imputabilidad Penal y neurociencias. La inimputabilidad por razones psiquiátricas a la luz de las neurociencias actuales. Ad. Hoc, Buenos Aires.

Tonkonoff, S. 2007. Acerca del crimen, el criminal y las reacciones que suscita. En Revista Delito y Sociedad, $\mathrm{N}^{\circ}$ 23.

Souza Lima, A. (comp). 2002. Gestar e Gerir: estudos para uma antropologia da administração pública no Brasil. Relume Dumará, (Coleção Antropologia da Política), Rio de Janeiro.

Van Dijk, T. A. 1999. El análisis crítico del discurso. En Revista Anthropos, N 186.

Vannini, F., Del Cero, M. y Saulnier, A. 2003. "Imputabilidad disminuida" en Revista electrónica Derecho Penal Online [en línea]. Disponible en: http://www.derechopenalonline.com

Visacovsky, S., Guber, R. y Gurevich, E. 1997. "Modernidad y tradición en el origen de la carrera de Ciencias Antropológicas de la Universidad de Buenos Aires" en Revista Redes, Volumen IV, N 10.

Zaffaroni, E. 2001. "Los aportes y desarrollos del poder judicial en la lucha contra la impunidad" en Méndez, J., Abregó, M, Mariezcurrena, J. 2001. Verdad y Justicia. Homenaje a Emilio F. Mignone. IIDH, CELS. 